\title{
Applying the coral reefs optimization algorithm for solving unequal area facility layout problems
}

\author{
L. Garcia-Hernandez ${ }^{\text {a,* }}$, L. Salas-Morera a, J.A. Garcia-Hernandez ${ }^{\text {a }}$, S. Salcedo-Sanz ${ }^{\text {, }}$, \\ J. Valente de Oliveira ${ }^{c}$ \\ a Area of Project Engineering, University of Cordoba, Spain \\ ${ }^{\mathrm{b}}$ Department of Signal Processing and Communications, Universidad de Alcalá, 28805 Alcalá de Henares, Madrid, Spain \\ c University of Algarve, Portugal
}

\section{A R T I C L E I N F O}

\section{Article history:}

Received 17 January 2019

Revised 9 July 2019

Accepted 15 July 2019

Available online xxx

\section{Keywords:}

Unequal area facility layout problem

Coral reefs optimization

Facility layout

Meta-heuristic

Bio-inspired algorithms

\begin{abstract}
A B S T R A C T
Coral Reefs Optimization (CRO) is a recently proposed evolutionary-type algorithm which has shown promising results to tackle many complex optimization problems. This paper discusses the performance of this meta-heuristic in Unequal Area Facility Layout Problems (UA-FLPs). The UA-FLP is an important problem in industrial production, which considers a rectangular region and a set of rectangular facilities. These facilities must be allocated in the plant in the most adequate way satisfying certain constraints. The Flexible Bay Structure has been selected in order to represent solutions for the UA-FLP in the proposed CRO algorithm. In this paper, we detail the implementation of the algorithm and provide the results of different tests in several UA-FLP instances with different size and setting. The obtained results confirm the excellent performance of the proposed algorithm in solving UA-FLPs, improving alternative algorithms devoted to this problem in the literature.
\end{abstract}

(c) 2019 Elsevier Ltd. All rights reserved.

\section{Introduction}

Facility Layout Design (FLD) decides the allocation of departments (or facilities) in a manufacturing layout, trying to reach well laid out facilities taking into account some objectives or criteria, under certain constraints. Considering Tompkins, White, Bozer, and Tanchoco (2010), a good distribution of the departments implies improvements in the efficiency and can decrease the total expenses in a company between $20 \%$ and 50\%. For this reason, FLD is a very important issue to consider in order to reduce expenses and other work resources in a manufacturing (Kouvelis, Kurawarwala, \& Gutierrez, 1992). There are many different Facility Layout Problems (FLPs) in FLD applications, which are determined by several features and design factors. In this respect, it is possible to find some classifications and taxonomies for FLPs in the works by Drira, Pierreval, and Hajri-Gabouj (2007), Hosseini-Nasab, Fereidouni, Fatemi Ghomi, and Fakhrzad (2018) and Anjos and Vieira (2017), among others. A particularly interesting FLP, due to its direct application to real cases, is known as Unequal Area Facility Layout Problem (UA-FLP).

\footnotetext{
* Corresponding author.

E-mail addresses: ir1gahel@uco.es (L. Garcia-Hernandez), Isalas@uco.es (L. SalasMorera), sancho.salcedo@uah.es (S. Salcedo-Sanz).
}

The UA-FLP was first described by Armour and Buffa (1963), and it takes into account an industrial plant and a set of unequal departments, both of them with rectangular shape. Then, the facilities must to be allocated adequately in the layout. As main constraints, in this version of FLP the overlap between facilities is not allowed and, in addition, they must be allocated within the boundary of the space plant layout. Normally, the main objective of UA-FLP is to minimize the cost of material flow between the departments that make up the industrial plant. (Gonçalves \& Resende, 2015).

Different approaches have been recently applied aiming at solving the UA-FLP. In Komarudin and Wong (2010) it is established that it is possible to classify the approaches that solve this problem into deterministic procedures and heuristics/metaheuristics methods. Taking into consideration the deterministic methods, Meller, Narayanan, and Vance (1998) suggested a branch and bound approach that included a structure with an acyclic subgraph for solving this problem. In this sense, Montreuil (1991) and Konak, Kulturel-Konak, Norman, and Smith (2006) applied to UAFLPs a proposal based on mixed integer programming. Afterward, Meller et al. (1998) modified Montreuil's proposal in order to solve large UA-FLPs. They reached an optimal solution for a UA-FLP with eight facilities. Later, Sherali, Fraticelli, and Meller (2003) suggested a upgraded model that solved more efficiently UA-FLPs by means of decreasing the amount of error. Moreover, Castillo, Westerlund, Emet, and Westerlund (2005) reached 
optimal solution solving an UA-FLP of nine facilities using the same approach than Sherali et al. (2003) with some improvements. Recently, Saraswat, Venkatadri, and Castillo (2015) and Purnomo and Wiwoho (2016) used the proposal taken from Sherali et al. (2003) in order to consider more than one objective. Chae and Regan (2016) reached optimal designs for problems up to 12 facilities. They also considered both fixed and flexible dimensions for facilities.

In general, meta-heuristics methods perform better than deterministic algorithms for UA-FLPs, mainly in large and very large instances. That is why heuristic and meta-heuristic approaches have been more frequently used for solving UA-FLPs. For example, Tam (1992) developed a Simulated Annealing approach called LOGIC in order to find best solutions for this problem. More recently, Scholz, Petrick, and Domschke (2009) and KulturelKonak (2012) proposed Tabu search proposals for the UA-FLP.

Many researches have employed Genetic Algorithms (GAs) for solving UA-FLPs. This way, Tate and Smith (1995) suggested a GA that included a penalty function in order to focus the process of finding solutions only to the feasible ones. Azadivar and Wang (2000) addressed the UA-FLP by means of a GA that used a Slicing Tree Structure as layout representation. Considering aisles in the UA-FLP, Wu and Appleton (2002) and Gomez, Fernandez, De la Fuente Garcia, and Garcia (2003) proposed GA approaches for solving this problem. Enea, Galante, and Panascia (2005) used a GA to UA-FLP considering a fuzzy environment and also aspect ratio constraints. Moreover, Aiello, Enea, and Galante (2006) implemented a combination of a GA and Electre algorithm to address the UA-FLP. Liu and Meller (2007) applied an approach that combined Mixed-Integer Programming and GA to solve this problem. They deleted unfeasible features in order to easily solve the problem. Continuing with genetic approaches applied to this problem, García-Hernández, Pierreval, Salas-Morera, and ArauzoAzofra (2013b) suggested an approach that combined Interactivity and a GA for capturing those features that the Decision Maker (DM) preferred in a particular solution. Their Interactive Genetic Algorithm was improved by García-Hernández, PalomoRomero, Salas-Morera, Arauzo-Azofra, and Pierreval (2015) for achieving more diversity in the final layout solutions. In this respect, García-Hernández, Arauzo-Azofra, Salas-Morera, Pierreval, and Corchado (2015) reached an improvement by means of considering both Decision Maker preferences and quantitative factors in the final solution. They achieved it through an interactive multi-objective GA. More recently, Palomo-Romero, Salas-Morera, and GarcíHernández (2017) suggested a proposal that improved the quantitative performance of many of tested UA-FLPs using a GA based on an Island Model to explore different individuals from the varying search context.

Alternative meta-heuristics have also been used to address UA-FLPs. For example, ant colony optimization (Komarudin \& Wong, 2010) (Wong \& Komarudin, 2010) (Kulturel-Konak \& Konak, 2011) (Liu \& Liu, 2019), artificial immune system (Ulutas \& Kulturel-Konak, 2012), biased random-key GA (Gonçalves \& Resende, 2015), collision detection and response approach (Sikaroudi \& Shahanaghi, 2016), GA combined with a decomposition strategy (Paes, Pessoa, \& Vidal, 2017), among others. Finally, Kang and Chae (2017) solved UA-FLP by means of a modification of the Harmony Search method proposed by Shayan and Chittilappilly (2004). Additionally, they presented a new slicing tree representation for layout configuration.

In order to represent the plant layout design, some different approaches have been developed. The Block Layout Design Problem (BLDP) representation allows locating every facility in the plant freely in any position with the restriction of not overlapping with other facilities. In such representation, Mixed Integer Linear and Nonlinear Programming methods are used (Castillo et al., 2005;

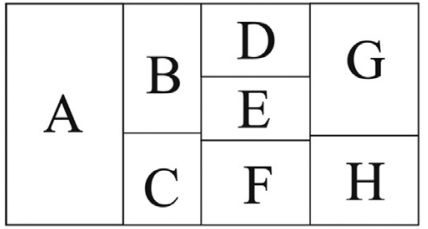

Fig. 1. Layout representation based on FBS.

Gonçalves \& Resende, 2015; Meller \& Gau, 1996). In the search for a representation more useful to apply evolutionary algorithms, two more facilities layout representations have been proposed: Slicing Tree Structure (STS) and Flexible Bay Structure (FBS). In STS, the space is recursively divided into vertical and horizontal sections (Kang \& Chae, 2017; Komarudin \& Wong, 2010; Scholz et al., 2009; Shayan \& Chittilappilly, 2004) while in FBS, the space is only divided into horizontal or vertical bands (Kulturel-Konak \& Konak, 2011; Meller, 1997). In this way, STS and FBS structures are not comparable nor in the way they use to locate the facilities in the plant, neither in the results obtained by each one of them.

A representation based on the Flexible Bay Structure (FBS) has been selected in this paper in order to represent a facility layout as an individual in an evolutionary-type algorithm. With respect to the advantages of using FBS as layout representation, it is can be stated that considering FBS as layout representation permits the UA-FLP become simpler and easier to be addressed, because of the UA-FLP complexity is decreased into determining the facilities location order and the total number of facilities that each bay will contain (Wong \& Komarudin, 2010). Additionally, this kind of representation which was suggested by Tong (1991) has been widely used among the different structures available from the related references (Liu \& Liu, 2019; Palomo-Romero et al., 2017; Wong \& Komarudin, 2010). This mechanism of illustrating plant layout consists of an area with rectangular shape that is vertically or horizontally split into sub-areas (called bays). Then, each one is split again to assign the departments that compose the manufacturing plant. According to Tate and Smith (1995), the generated subareas possess the property of having flexible width in order to have enough space for containing different number of facilities. Finally, according to Aiello, Scalia, and Enea (2012), using FBS offers an additional benefit due to it gives the possibility of incorporating aisles in an easy way. Fig. 1 shows a facility layout representation based on FBS. This FBS example has been taken from PalomoRomero et al. (2017).

In this work we test the performance of a different current evolutionary-based algorithm, the Coral Reefs Optimization (CRO) (Salcedo-Sanz, Del Ser, Landa-Torres, Gil-López, \& Portilla-Figueras, 2013) (Salcedo-Sanz, Del Ser, Landa-Torres, Gil-López, \& PortillaFigueras, 2014a) in order to address the UA-FLP. The CRO is an evolutionary-type algorithm which evolution is guided by imitating processes occurring in real coral reefs, such as reproduction, the fight for space or the predation. The CRO is an algorithm which results in a kind of hybrid Evolutionary Algorithm and Simulated Annealing (Salcedo-Sanz et al., 2014a), and it has been shown to improve both techniques in diverse instances in areas such as Telecommunications (Salcedo-Sanz, SanchezGarcia, J.A., Jimenez-Fernandez, \& Ahmadzadeh, 2014d) (SalcedoSanz, García-Díaz, Portilla-Figueras, Ser, \& Gil-López, 2014b), Energy (Salcedo-Sanz, Camacho-Gómez, Mallol-Poyato, JiménezFernández, \& DelSer, 2016) (Salcedo-Sanz, Pastor-Sánchez, Prieto, Blanco-Aguilera, \& García-Herrera, 2014c), Structural Engineering (Salcedo-Sanz, Camacho-Gómez, Magdaleno, Pereira, \& Lorenzana, 2017) (Camacho-Gómez, Wang, Pereira, Díaz, \& Salcedo-Sanz, 2018) or Bio-medical applications (Bermejo, Chica, Damas, SalcedoSanz, \& Cordón, 2018) (Yan, Ma, Luo, \& Patel, 2019). Recently,
111 


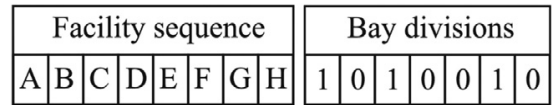

Fig. 2. Facility layout chromosome.

the CRO has also been used to different problems such as clustering (Medeiros, Xavier, \& Canuto, 2015), neural network training (Yang, Zhang, \& Zhang, 2016), time series analysis (DuránRosal, Gutiérrez, Salcedo-Sanz, \& Hervás-Martínez, 2018) or resource allocation problems (Ficco, Esposito, Palmieri, \& Castiglione, 2018), among others. In these works, the CRO has been successfully applied by reaching an excellent performance in the tested problem (Salcedo-Sanz, 2017). This work deals to investigate the performance of Coral Reefs Optimization addressing the UA-FLP. From the best of our knowledge, it is the first time that CRO is applied to solve the UA-FLP. We will show that the CRO algorithm is able to outperform other evolutionary based approaches in a number of large UA-FLP instances.

The remainder of this work has been organized as follows: Section 2 details the novel suggested approach for solving the UAFLP. Section 3 describes the experimental part of the work, with the results achieved in many different UA-FLPs. A comparison with published results reached by other approaches is carried out at this stage. Finally, Section 4 closes this research with a summary of the main concluding remarks and some future research lines that can be drawn based on this work.

\section{Proposed approach}

For addressing the UA-FLP we propose a new CRO approach which considers material flow as optimization criterion. Below, we will describe the algorithm's structure and implementation.

\subsection{Individual codification}

In order to encode an individual of the CRO reef, the chromosome structure suggested by Gomez et al. (2003) has been used. It is illustrated in Fig. 2. This encoding structure is formed by two different segments. The first one illustrates the sequence of departments in the facility layout, which is taken reading from top to bottom in each bay and reading the bay from left to right in the facility layout. An integer permutation from 1 to $n$ (being $n$ the total number of departments that exist in the layout) is employed in the first segment. The information about where are the cuts that delimit the bays of the layout is offered by the second segment. This one is composed by $(n-1)$ elements which have binary values. So that, if it is the value' 1 ' in a certain segment position means that the department in the same segment position of the first segment, is the last element of the bay. Else, it will appeared the value' 0 ' in the segment. Fig. 2 gives the individual chromosome associated to the facility representation offered in Fig. 1.

\subsection{Objective function}

Armour and Buffa (1963) stated the UA-FLP for the first time. The problem is defined by means of a rectangular layout of dimensions $(W \times H)$ which are fixed. Additionally, there is a group of facilities or departments with a determined area $\left(A_{i}\right)$. The sum of the department areas must be less or equal than the total area of the rectangular layout (see Eq. (1)).

$\sum_{i}^{n} A_{i} \leq W \times H$

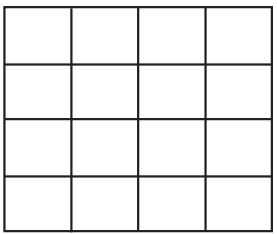

Fig. 3. Example of a coral reef with size $4 \times 4$.

The objective of the problem is to place all the departments 216 in the layout, optimizing a given criterion and taking into consid- 217 eration that overlapping between departments is not allowed. In 218 Aiello et al. (2012) it is stated that the UA-FLP involves as main 219 objective the minimization of the material flow between depart- 220 ments. The fitness score used in evolutionary algorithms to evalu- 221 ate UA-FLP test problems is therefore based on material flow. Ad- 222 ditionally, in order to guide the search process to feasible individ- 223 uals, a penalty function proposed by Tate and Smith (1995) have 224 been used. This way, for every solution in the algorithm, a penalty mark is defined, which is proportional to the number of facilities that make up the layout and that not satisfy the aspect ratio constraint (either the maximum aspect ratio or minimum side length). These facilities are considered as unfeasible. The fitness function that minimizes the material flow is the following:

$g(\mathbf{x})=\sum_{i}^{n} \sum_{j}^{n} f_{i j} d_{i j}+\left(D_{\text {inf }}\right)^{k}\left(V_{\text {feas }}-V_{\text {all }}\right)$

where $n$ is the number of departments in the layout, $f_{i j}$ is the material flow between the departments $i$ and $j, d_{i j}$ is the Manhattan distance between $i$ and $j$, Dinf is the number of facilities which are unfeasible, Vfeas is the best feasible fitness value that has been yet achieved, Vall is the best overall fitness value that has been yet achieved, an $k$ is a penalty parameter that fits the value of the penalty function (it has been set as 3 , following the suggestion in Tate \& Smith, 1995).

\subsection{The Coral Reef Optimization Algorithm}

The Coral Reef Optimization Algorithm (CRO) was recently proposed by Salcedo-Sanz et al. (2014a). This approach is a kind of evolutionary-type algorithm which imitates the evolution of coral reefs and the different processes occurring in these ecosystems. We will consider $\Lambda$ as a model of the reef with size of $N \times M$ square grid (see Fig. 3). Each square located in $\Lambda(i, j)$ is a place that can host a coral $\Xi(i, j)$ where $i$ and $j$ are the coordinates of the square in the reef. Each coral is a representation of a solution to our problem, in our particular case, a plant layout solution for the UA-FLP. Once we have modeled the reef and the corals itself, the algorithm process is define using the steps that are detailed as follows.

\subsubsection{Initialization of the algorithm}

One of the most important parameters of the CRO algorithm is the number of initial corals in the reef. A rate specifying the proportion between empty and in-use squares in the reef is defined, $\rho_{0}$, in such a way that $0<\rho_{0}<1$. Taking into consideration this parameter, the initial number of corals is calculated as:

InitialCorals $=N \times M \times \rho_{0}$

The initial corals are randomly generated and placed (also in a random way) in empty squares of the reef. Fig. 4 illustrates a coral reef initialized with random corals in a proportion of $0.5^{\prime}$ ' between empty and in use squares, i.e. $\rho_{0}=0.5$. This step is summarized in Algorithm 1. Once the reef are initialized, the simulation of the corals' evolution starts with an iterative execution of the corals' reproduction, which is realized by means of diverse operators until 

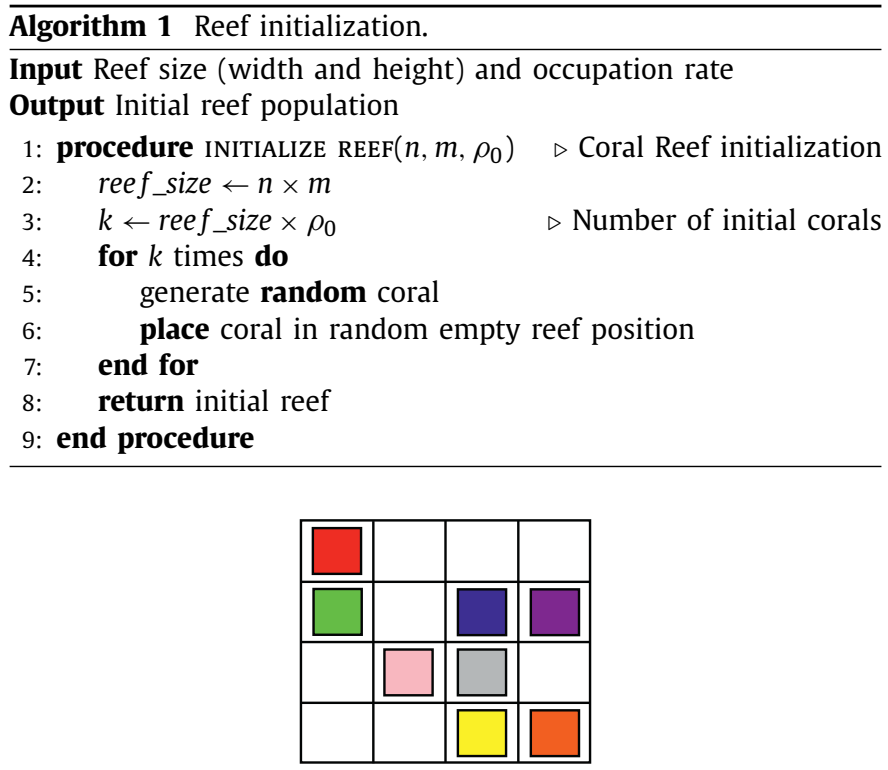

Fig. 4. Example of a coral reef with random individuals inserted and $\rho_{0}=0.5$.

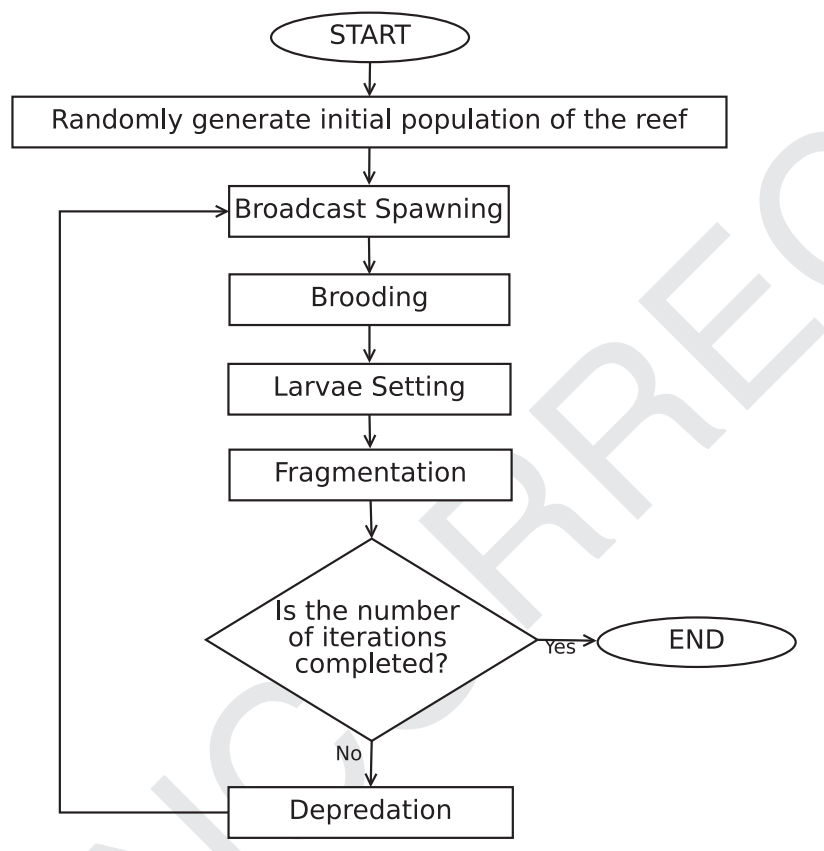

Fig. 5. Proposed CRO algorithm flowchart diagram.

the stop criterion is reached (in our particular case, when the required number of iterations have been satisfied). This iterative process (detailed in Salcedo-Sanz et al., 2014a) will be described in the following section.

\subsubsection{Iterative coral evolution}

The reproduction phase is defined by different operators for modeling Sexual Reproduction (that can be external and internal) and Asexual Reproduction. All these kind of reproduction phases will generate new corals from the existing ones in the reef which will be denoted as larvae. Between sexual and asexual reproduction phases, is the Larvae Setting step, where some of the new larvae elements will take place into the coral reef. Finally, a depredation phase will eliminate the weakest corals in the reef. Fig. 5 summarizes the entire process of the CRO algorithm. Additionally,
Algorithm 2 shows the flowchart diagram of the CRO algorithm 278 with the different CRO phases which are detailed below.

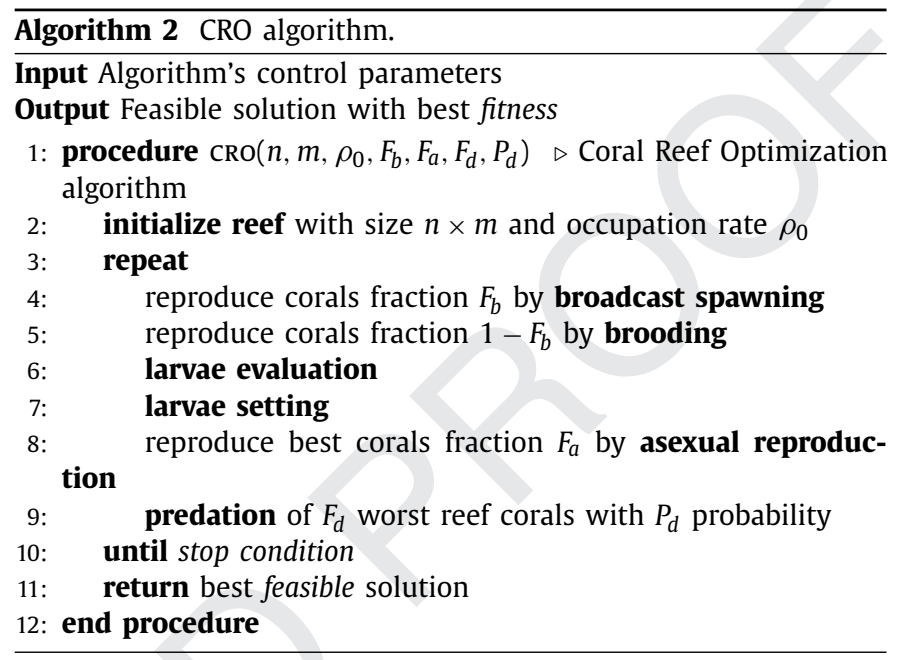

1. Broadcast spawning (External sexual reproduction) This phase is made up by two steps. Firstly, a number of the 281 corals that exist in the reef, denoted by $\rho_{k}$, is selected randomly 282 to be broadcast spawners. This fraction of broadcast spawners is 283 calculated with respect to the overall amount of existing corals 284 in the reef and it is denoted as $F_{b}$. The remaining corals which 285 have not been chosen for being broadcast spawners $\left(1-F_{b}\right)$ will 286 be selected for being reproduced in the brooding phase. Secondly, from the broadcast spawners $\left(\rho_{k}\right)$, the algorithm will select couples of corals in order to be reproduced. This selection of corals is random and with replacement, once a couple is selected, it can not be selected again for being reproduced in the same step. Each of the selected couples will form two children by sexual crossover. Specifically in our approach, the PartiallyMapped Crossover operator (PMX) proposed by Goldberg and robert (1985), is used for the facility sequence segment, and the One Point Crossover (Holland, 1992) is applied over the split segment. Then, a child will be randomly selected as coral larva which is then released out to the water. This crossover process is illustrated in Fig. 6 where it is shown how the layout representations change during CRO algorithm. The larvae result is stored until the Larvae Setting phase. Fig. 7 and Algorithm 3 detail the broadcast spawning phase.

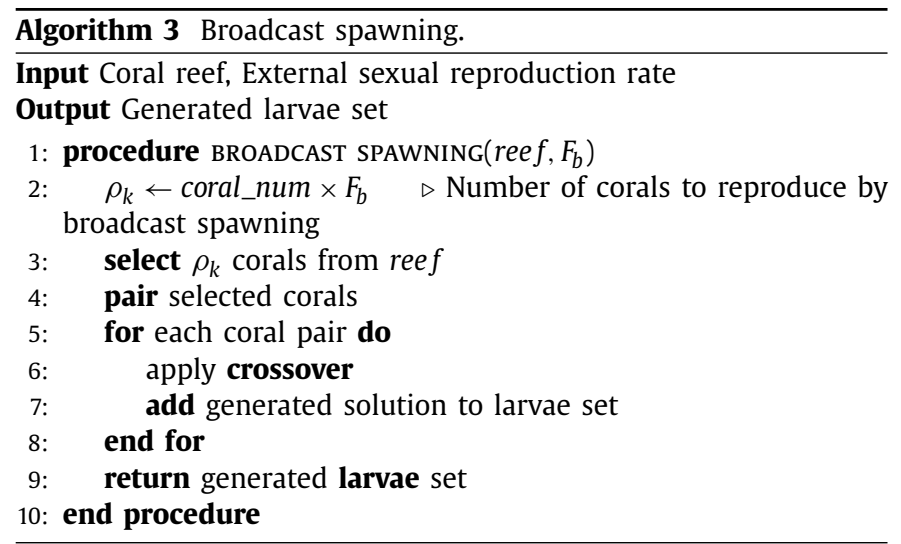

2. Brooding (Internal sexual reproduction) The remaining corals of the previous phase $\left(1-F_{b}\right)$ are selected 304 to be reproduced by brooding, which consist of the formation 305 


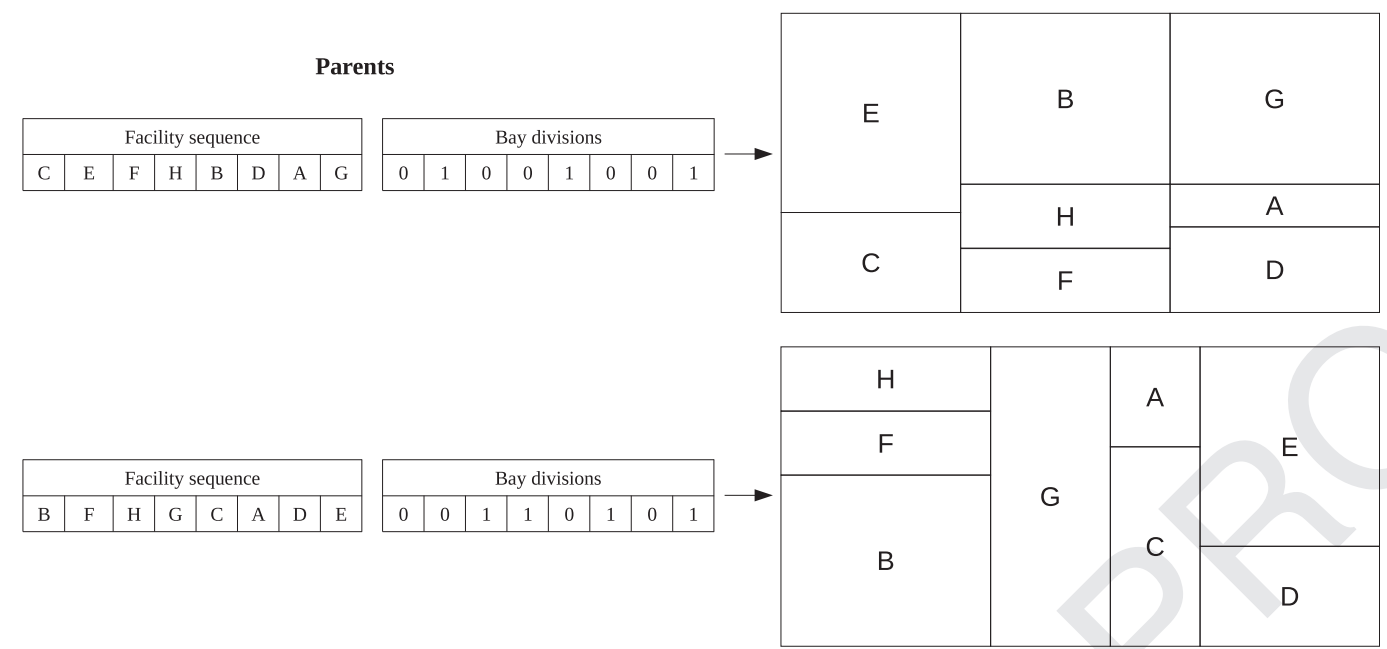

Crossover operator
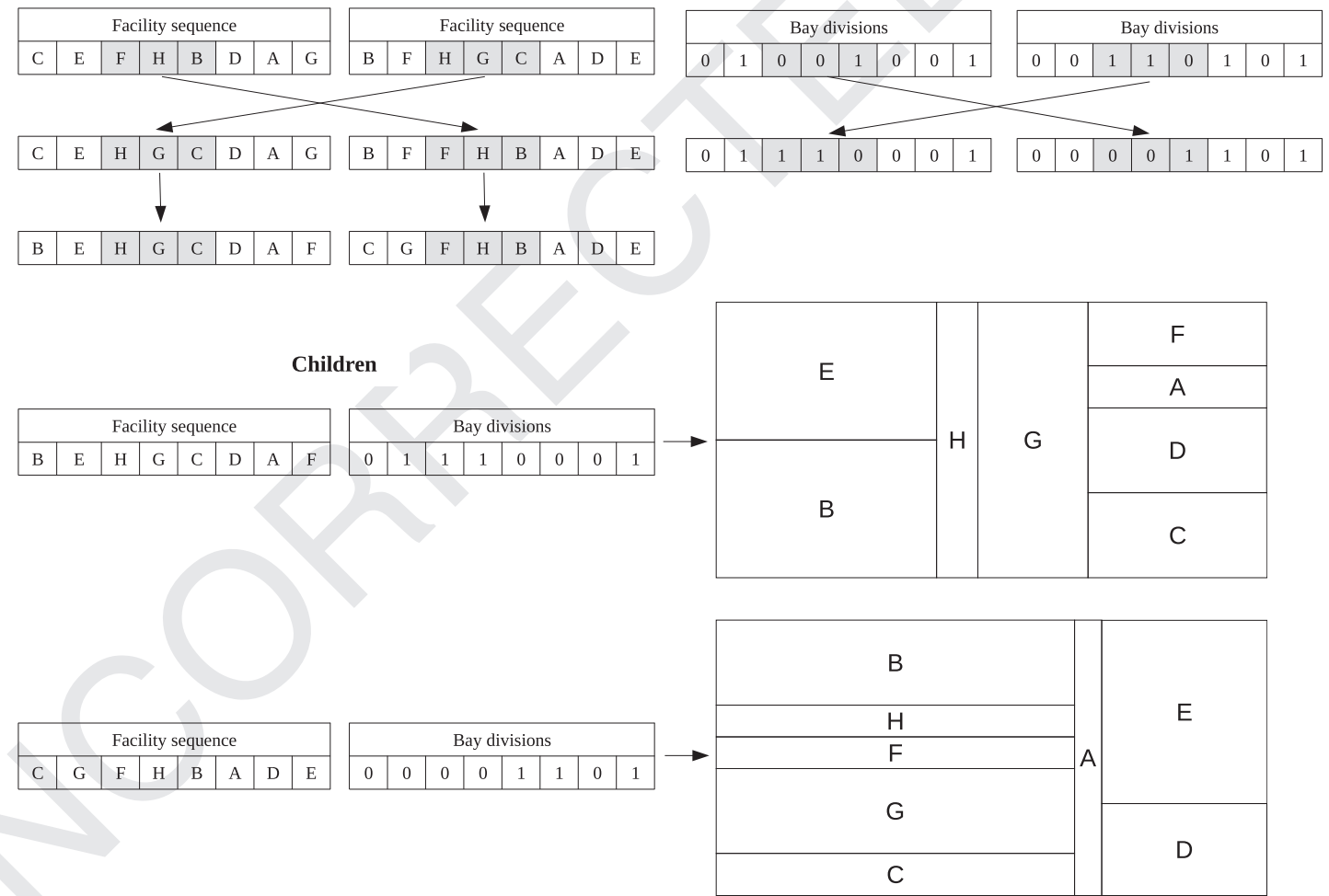

Fig. 6. Graphical diagram that illustrates Crossover process in Broadcast Spawning step.

of a coral larva by means of a random mutation in each $1-F_{b}$ coral element. The obtained larvae is then released out to the water in a similar way than it is performed in the previous phase. Fig. 9 shows brooding reproduction over the two corals which have not been selected to be reproduced in the previous phase (Fig. 7). This mutation process is illustrated using Fig. 8 where it is shown how the layout representations change again during CRO algorithm. Moreover, Algorithm 4 expresses how this phase is performed. The resulting larvae is stored until the Larvae Setting phase.

3. Larvae setting

At this moment, all the larvae created by Broadcast Spawning or Brooding are stored. Then, the next step consists of trying to set

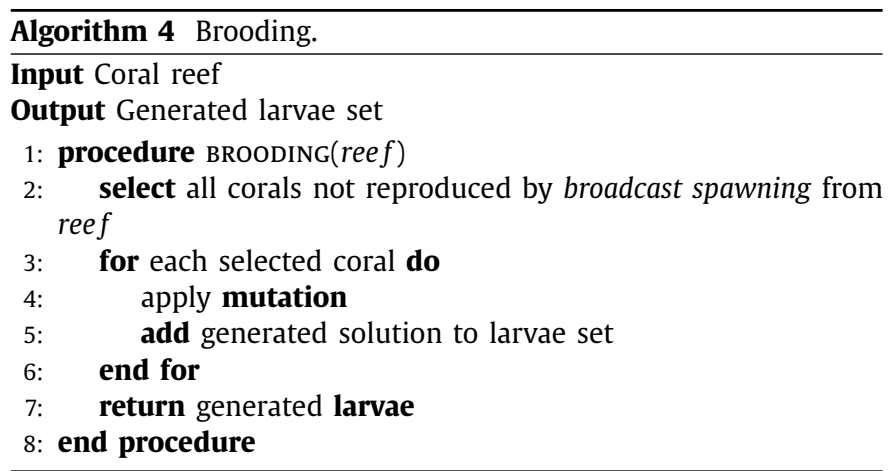




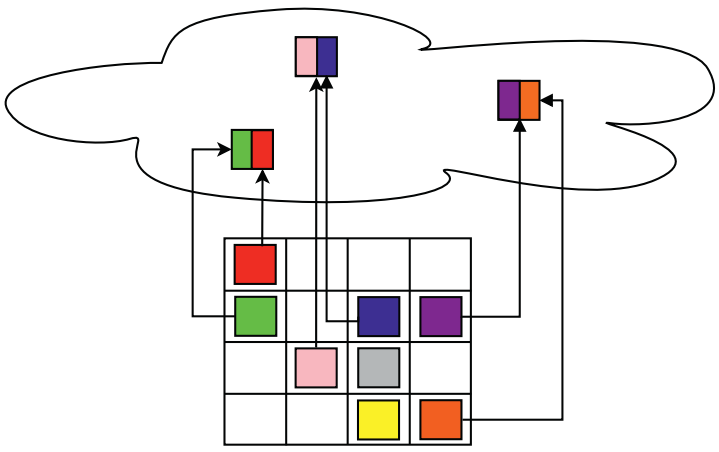

Fig. 7. Graphical diagram that illustrates Broadcast Spawning step. and grow those larvae into the reef. For that matter, the fitness function for both larvae and corals that exist in the reef is computed (in our particular case, the fitness function is the existing material flow between the departments that compose the plant layout). Then, a larva is selected to be placed in a random location of the reef. If this position is free, the larva will be allocated there. If it is not, the fitness of the coral and the larva will be compared. This way, if the larva fitness is better (it has less value of material handling cost) than the coral, the coral will be replaced by the larva. If the larva does not replace the coral (it has higher value of material handling cost), it will try $\kappa$ times (this number is ' 3 ' as suggested by Salcedo-Sanz et al., 2013) to be placed in another position of the reef. If the larva can not be placed in $\kappa$ attempts, it will be deprecated. This mechanism is explained by means of Fig. 10 and Algorithm 5 .

4. Budding or fragmentation (Asexual reproduction)

In this phase, all the existing corals in the reef are ranked as a function of their level of fitness. Then, a fraction of them denoted by $F_{a}$, is duplicated itself and tries to be allocated in a different square in the reef. This is performed by means of the same process that has been explained in the Larvae Set-

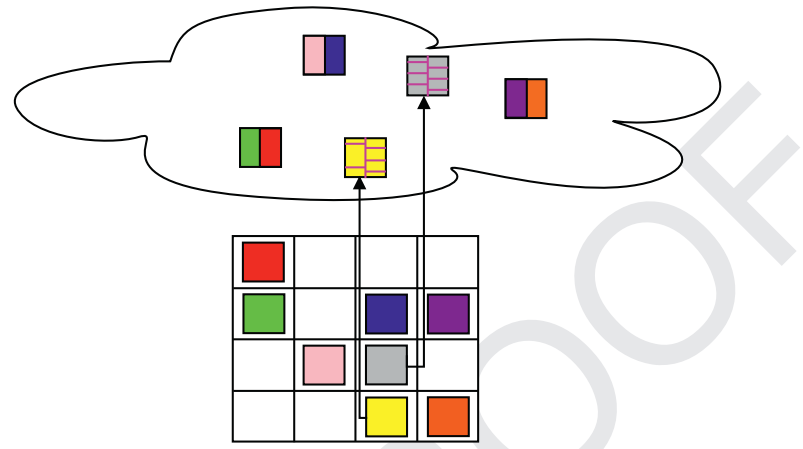

Fig. 9. Graphical diagram that illustrates Brooding phase.

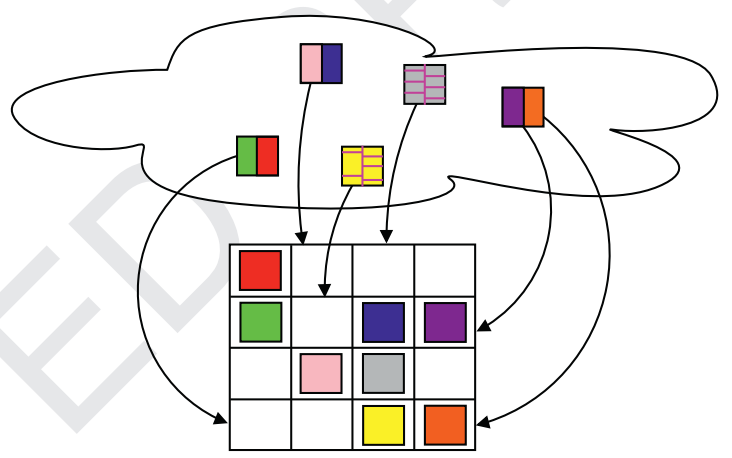

Fig. 10. Graphical diagram that illustrates larvae setting phase.

ting phase. This asexual reproduction is illustrated by means of 340 Fig. 11 and Algorithm 6.

5. Depredation 342 At the end of each algorithm iteration, a fraction of the worse 343 fitness corals denoted by $F_{d}$ that exist in the reef will be depre- 344 cated with a very low probability denoted by $P_{d}$. This liberates 345 space in the reef for next coral generation. Depredation step is 346 shown using Fig. 12 and Algorithm 7.

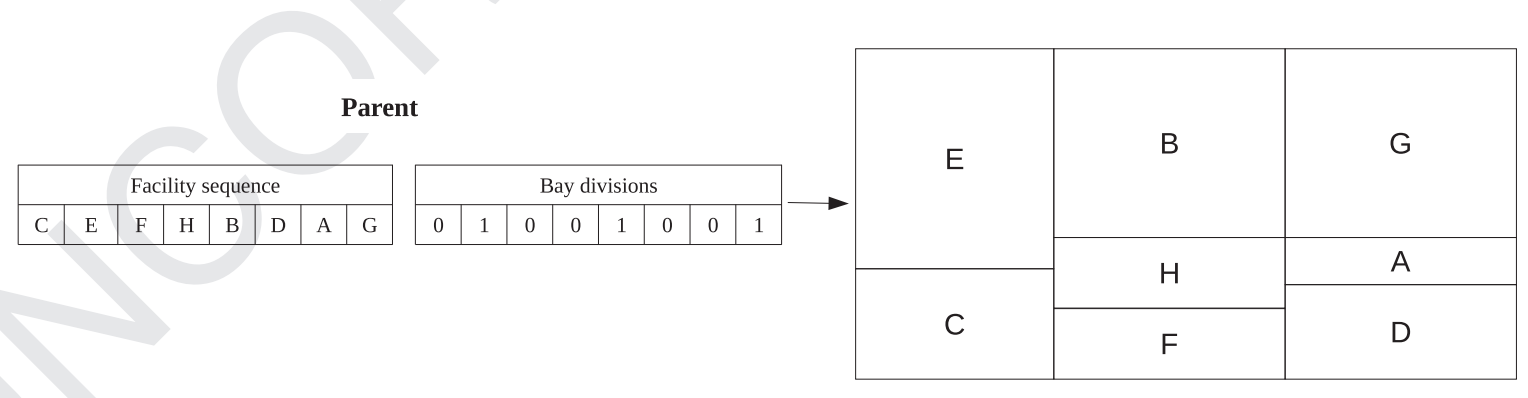

Mutation operator

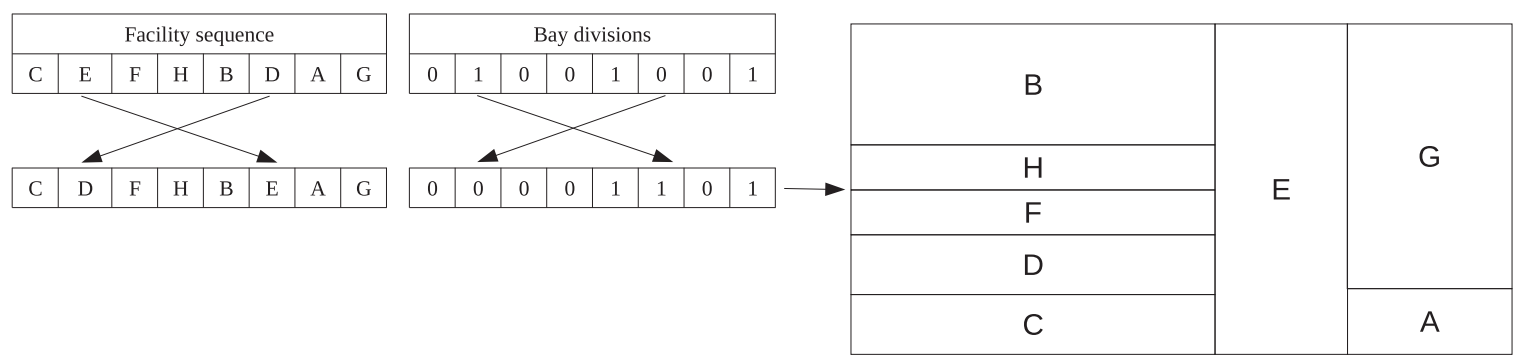

Fig. 8. Graphical diagram that illustrates Mutation process in Brooding step. 


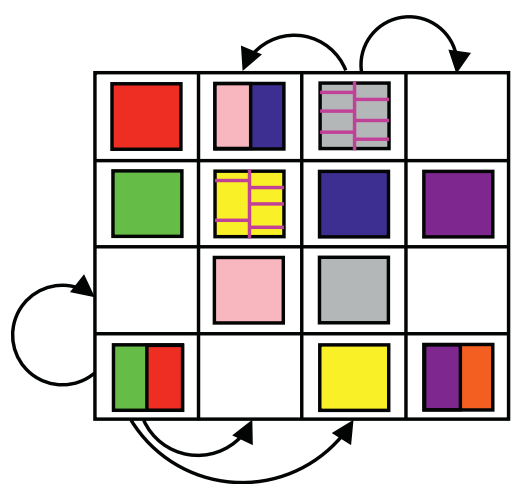

Fig. 11. Graphical diagram that illustrates budding phase.
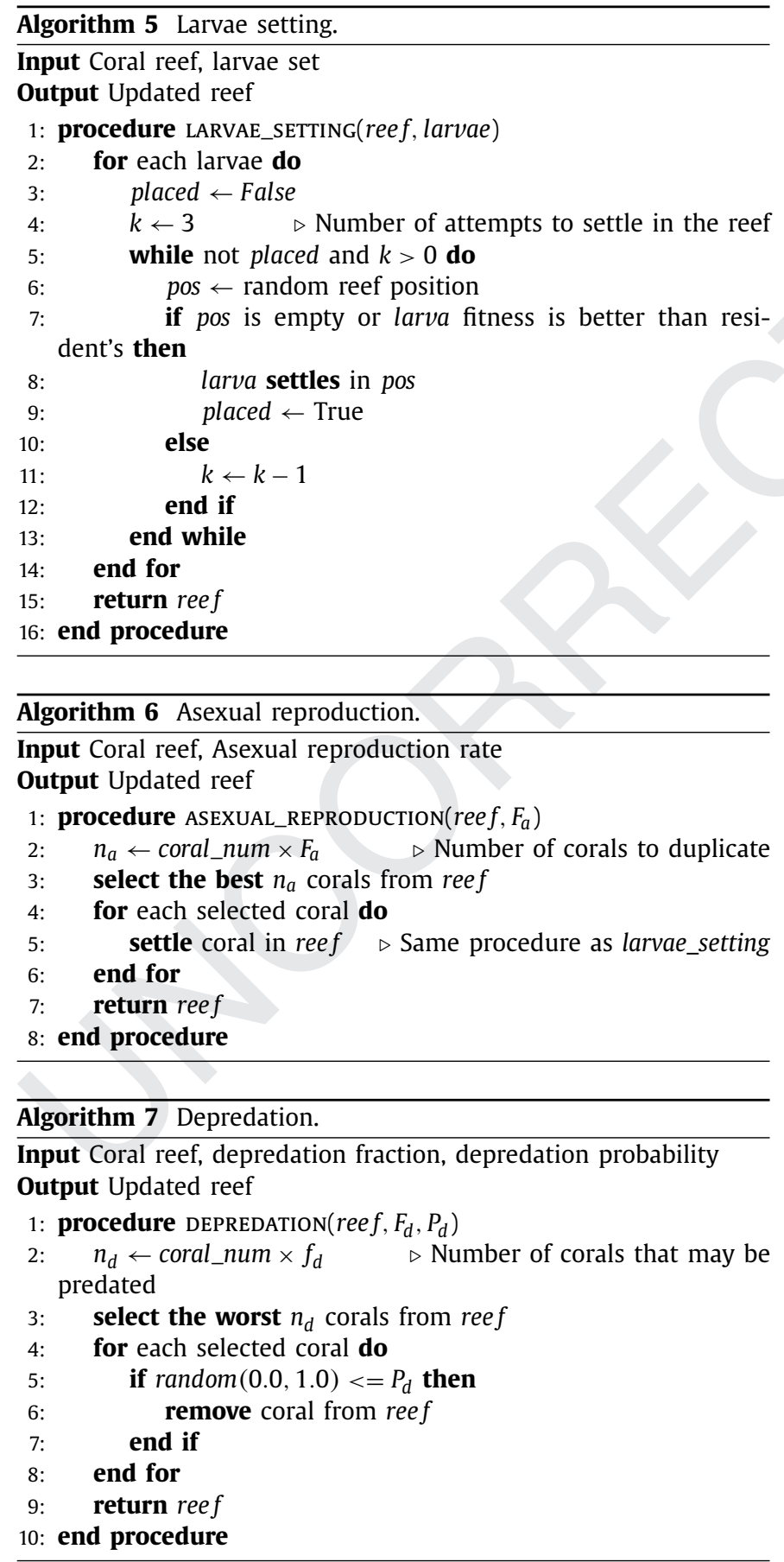

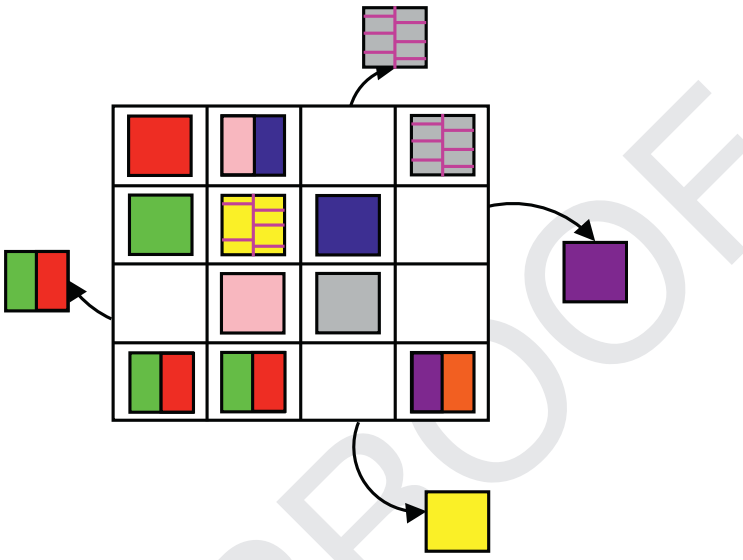

Fig. 12. Graphical diagram that illustrates depredation step.

\section{Experimental set and results obtained}

The performance of the proposed CRO approach is tested in comparison with state-of-the-art algorithms for the UA-FLP in this section. For this, we have used many UA-FLP instances taken from other works of related references. The set of well-known UA-FLPs are: Slaughterhouse detailed in Salas-Morera, CuberoAtienza, and Ayuso-Munoz (1996); CartonPacks and ChoppedPlastic from García-Hernández, Arauzo-Azofra, Salas-Morera, Pierreval, and Corchado (2013a); 07, 08 and 09, described by Meller et al. (1998); VC10 (both side and aspect ratio constraints) illustrated in van Camp, Carter, and Vannelli (1992); MB12 explained by Bozer and Meller (1997); Ba12 detailed in Bazaraa (1975); Ba14 presented in Komarudin and Wong (2010) of the problem described in Bazaraa (1975); Ma15 (with two different shape constraints) from Bozer, Meller, and Erlebacher (1994); AB20 detailed by Armour and Buffa (1963); SC30, a modification taken from Komarudin and Wong (2010) of the problem described in Liu and Meller (2007); SC35 from Liu and Meller (2007); and DU62 described by Dunker, Radons, and Westkämper (2003).

The characteristics of the selected UA-FLPs for being tested are described in Table 1. This information is the UA-FLP name, number of facilities, facility width, facility height, shape constraint (being $\alpha$ the maximum aspect ratio constraint, and Imin the minimum side length constraint), and finally the references for the problem data sources. Note that the used measure distance is the Manhattan as default parameter. However, the Euclidean distance have been applied to the instances of Slaughterhouse, Carton Packs and Chopped Plastic. Note that Ba14 problem has two different values for the minimum side length constraint which is' 1' for the departments that are from 1 to 12 , and, it is' 0 ' for the departments 13 and 14.

The proposed CRO performance deeply depends on a set of parameters. We have tuned them in an empirical way. Thus, we have performed different checks in order to reach the best set of values for the algorithm in the UA-FLP. Table 2 illustrated the best values obtained for the CRO parameters. Taking into consideration the values express in Table 2, a full-factorial experiment has been performed testing sets of UA-FLPs with each possible combination of parameters. Specifically, the representative sets of UA-FLPs which have been selected for tuning our CRO algorithm have been 09 from Meller et al. (1998), Ma15a taken from Bozer et al. (1994) and SC30 taken from Liu and Meller (2007). These problems have been chosen as representative ones in order to consider the different department sizes (small, medium and large) of the UA-FLPs. Then, a comparison between the reached solutions has been done in order to select which parameter option fits better. The best CRO configu- 
Table 1

Features of the tested well-known problems.

\begin{tabular}{lllll}
\hline Problem name & Fac. & $W \times H$ & Aspect ratio & Reference \\
\hline Slaughterhouse & 12 & $51.14 \times 30.00$ & $\alpha=4$ & Salas-Morera et al. (1996) \\
CartonPacks & 11 & $20.00 \times 14.50$ & $\alpha=4$ & García-Hernández et al. (2013a) \\
ChoppedPlastic & 10 & $10.00 \times 30.00$ & $\alpha=4$ & García-Hernández et al. (2013a) \\
O7 & 7 & $8.54 \times 13.00$ & $\alpha=4$ & Meller et al. (1998) \\
O8 & 8 & $11.3 \times 13.00$ & $\alpha=4$ & Meller et al. (1998) \\
O9 & 9 & $12.00 \times 13.00$ & $\alpha=4$ & Meller et al. (1998) \\
vC10Ra & 10 & $25.00 \times 51.00$ & $\alpha=5$ & van Camp et al. (1992) \\
Vc10Rs & 10 & $25.00 \times 51.00$ & Min.side=5 & van Camp et al. (1992) \\
Ba12 & 12 & $6.00 \times 10.00$ & Min.side=1 & Bazaraa (1975) \\
MB12 & 12 & $6.00 \times 8.00$ & $\alpha=4$ & Bozer and Meller (1997) \\
Ba14 & 14 & $7.00 \times 9.00$ & Min.side=\{1,0\} & Komarudin and Wong (2010) \\
Ma15 & 15 & $15.00 \times 15.00$ & $\alpha=5$ & Bozer et al. (1994) \\
Ma15s & 15 & $15.00 \times 15.00$ & Min.side=1 & Bozer et al. (1994) \\
AB20 & 20 & $2.00 \times 3.00$ & $\alpha=5$ & Armour and Buffa (1963) \\
SC30 & 30 & $12.00 \times 15.00$ & $\alpha=5$ & Liu and Meller (2007) \\
SC35 & 35 & $16.00 \times 15.00$ & $\alpha=4$ & Liu and Meller (2007) \\
Du62 & 62 & Arbitrary $\times$ Arbitrary & $\alpha=4$ & Dunker et al. (2003) \\
\hline
\end{tabular}

Table 2

CRO parameters selection.

\begin{tabular}{|c|c|c|c|c|c|c|}
\hline \multirow[t]{2}{*}{ UA-FLP } & \multicolumn{3}{|c|}{ Chosen values } & \multirow{2}{*}{\multicolumn{2}{|c|}{$\begin{array}{l}\text { Tested values } \\
\text { Combination of: }\end{array}$}} & \\
\hline & 09 & Ma15s & SC30 & & & \\
\hline $\mathrm{N} \times \mathrm{M}$ & $25 \times 25$ & $25 \times 25$ & $25 \times 25$ & $10 \times 10$ & $15 \times 15$ & $25 \times 25$ \\
\hline$\rho_{0}$ & c0.4 & 0.4 & 0.4 & 0.4 & 0.5 & 0.6 \\
\hline$F_{b}$ & c0.9 & 0.9 & 0.9 & 0.8 & 0.85 & 0.9 \\
\hline$F_{a}$ & c0.1 & 0.1 & 0.2 & 0.1 & 0.15 & 0.2 \\
\hline$F_{d}$ & 0.1 & 0.1 & 0.1 & 0.01 & 0.05 & 0.1 \\
\hline$P_{a}$ & c0.1 & 0.1 & 0.1 & 0.01 & 0.05 & 0.1 \\
\hline
\end{tabular}

Table 3

Statistical results reached by the CRO algorithm.

\begin{tabular}{llll}
\hline Problem name & OFV Best & OFV Mean & CPU(s) \\
\hline Slaughterhouse & 3487.12 & 3487.12 & 78.00 \\
CartonPacks & 80.91 & 80.91 & 74.00 \\
ChoppedPlastic & 265.77 & 265.77 & 65.00 \\
O7 & 134.16 & 134.16 & 4.00 \\
O8 & 245.48 & 245.48 & 24.00 \\
O9 & 239.44 & 239.44 & 49.00 \\
vC10Ra & 20142.13 & 20576.93 & 61.00 \\
Vc10Rs & 22897.65 & 22898.65 & 63.00 \\
Ba12 & 8021.0 & 8103.96 & 87.00 \\
MB12 & 125.00 & 125.00 & 81.00 \\
Ba14 & 4665.93 & 4731.23 & 92.00 \\
Ma15 & 26800.63 & 26972.95 & 104.00 \\
Ma15s & 22871.97 & 23034.88 & 106.00 \\
AB20 & 5243.95 & 5250.02 & 202.00 \\
SC30 & 3519.44 & 3566.27 & 622.00 \\
SC35 & 4263.3 & 4409.34 & 552.00 \\
Du62 & 713876.55 & 3719342.03 & 871.00 \\
\hline
\end{tabular}

ration for each representative UA-FLP instance has been shown in the column 'Chosen value'.

The experimentation has been replicated five times for each UA-FLP like in Komarudin and Wong (2010) with a stopping criteria of 10,000 iterations as maximum and 500 iterations without improvement. The CRO algorithm was coded with Python 2.7.3. All experiments were performed using an Intel Core i5 6200U $(2.30 \mathrm{GHz} \times 4), 8 \mathrm{~GB}$ RAM and a Linux operating system.

\subsection{Results}

Table 3 presents the statistical results obtained by the suggested CRO algorithm. For each UA-FLP, the best objective function value (best OFV), the mean objective function value (mean OFV) and CPU time (in seconds) for reaching the best objective function value, are detailed. From the table, it can be extract that the
CRO algorithm is robust because of the percentage of gap between the best and mean objective function value is relatively low. This gap usually increases as the number of facilities increases in the UA-FLP. Regarding CPU time, See and Wong (2008) stated that in facility layout design the CPU time is not an extremely important issue. In this context, our proposal is able to reach satisfactory solutions in an reasonable CPU time if it is compared to alternative approaches (as for instance Komarudin \& Wong, 2010; PalomoRomero et al., 2017, among others).

A comparison of the results reached by our CRO algorithm and the results taken from related references that uses both FBS and STS, have been performed in order to analyze the performance of the proposed CRO approach. This information is shown by means on Tables 4 and 6 . The first one (Table 4) offers for each data set problem the following information: The best known solution result, its associated layout representation, and also, the reference of the paper that obtained it. Additionally, taking into account that we have used FBS as layout representation in our approach, Table 4 also presents for each problem, the best known solution results and their associated reference considering particularly FBS as layout representation. In this table, we have set in bold font those results reached by our proposed approach which are the best known results. This way, regarding Tables 4 and 5, it can be seen that our proposal reaches or improves the best solution fitness in 7 cases out of 17 tested problems when considering both STS and FBS as layout representation. This fact (our proposal reaches or improves the best solution) happens in 14 cases out of 17 tested problems when we consider exclusively FBS representation. In the remaining cases, our approach is able to reach solutions very close to the best known ones.

According with Kang and Chae (2017) the STS can reach layout solutions that cannot be represented by means of FBS. That is the reason why in most cases, the solutions obtained using STS achieve better results than those that are reached using FBS. For this reason, we consider interesting to analyze the result compar- 
Table 4

Summary of test problems and their best-known and best-known FBS solutions.

\begin{tabular}{llllll}
\hline Problem & Best known & Layout represent. & Reference & Best known FBS & Reference \\
\hline Slaughterhouse & $\mathbf{3 4 8 7 . 1 2}$ & FBS & This approach & $\mathbf{3 4 8 7 . 1 2}$ & This approach \\
CartonPacks & $\mathbf{8 9 . 0 2}$ & FBS & This approach & $\mathbf{8 9 . 0 2}$ & This approach \\
ChoppedPlastic & $\mathbf{2 6 5 . 7 7}$ & FBS & This approach & $\mathbf{2 6 5 . 7 7}$ & This approach \\
O7 & 131.56 & STS & Gonçalves and Resende (2015) & $\mathbf{1 3 4 . 1 6}$ & This approach \\
O8 & 243.12 & STS & Wong and Komarudin (2010) & $\mathbf{2 4 5 . 4 8}$ & This approach \\
O9 & 236.14 & STS & Kang and Chae (2017) & $\mathbf{2 3 9 . 4 4}$ & This approach \\
Vc10Ra & 18522.79 & STS & Kang and Chae (2017) & $\mathbf{2 0 1 4 2 . 1 3}$ & This approach \\
Vc10Rs & 19951.17 & STS & Gonçalves and Resende (2015) & $\mathbf{2 2 8 9 7 . 6 5}$ & This approach \\
Ba12 & $\mathbf{8 0 2 1 . 0}$ & FBS & This approach & $\mathbf{8 0 2 1 . 0}$ & This approach \\
MB12 & $\mathbf{1 2 5 . 0 0}$ & FBS & This approach & $\mathbf{1 2 5 . 0 0}$ & This approach \\
Ba14 & 4628.79 & STS & Gonçalves and Resende (2015) & $\mathbf{4 6 6 5 . 9 3}$ & This approach \\
Ma15a & $\mathbf{2 6 8 0 0 . 6 3}$ & FBS & This approach & $\mathbf{2 6 8 0 0 . 6 3}$ & This approach \\
Ma15s & $\mathbf{2 2 8 7 1 . 9 7}$ & FBS & This approach & This approach \\
AB20 & 4959.11 & STS & Kang and Chae (2017) & $\mathbf{5 2 4 3 . 9 5}$ & This approach \\
SC30 & 3352.70 & STS & Kang and Chae (2017) & Kulturel-Konak and Konak (2011) \\
SC35 & 3316.77 & STS & Gonçalves and Resende (2015) & 3613.11 & Kulturel-Konak and Konak (2011) \\
Du62 & 3635307.0 & STS & Kang and Chae (2017) & 3641497.00 & Kulturel-Konak and Konak (2011) \\
\hline
\end{tabular}

Table 5

Test result comparisons between the best solutions reached by our CRO algorithm and alternative published FBS approaches.

\begin{tabular}{|c|c|c|c|c|c|c|}
\hline Problem & CRO & Palomo(2017) & Kulturel-Konak (2011) & Kulturel-Konak (2012) & Wong (2010) & Enea (2005) \\
\hline Slaughterhouse & 3487.12 & - & - & - & - & 3854.00 \\
\hline CartonPacks & 89.02 & - & - & - & - & 94.10 \\
\hline ChoppedPlastic & 265.77 & - & - & - & - & 377.18 \\
\hline 07 & 134.16 & 134.19 & - & - & - & - \\
\hline 08 & 245.48 & 245.51 & - & - & - & - \\
\hline 09 & 239.44 & 241.06 & - & - & 241.06 & - \\
\hline Vc10Ra & 20142.13 & 20142.13 & 20142.13 & 21463.07 & 21463.1 & - \\
\hline Vc10Rs & 22897.65 & 22899.65 & 22899.65 & 22899.65 & 22899.65 & - \\
\hline Ba12 & 8021.0 & 8435.83 & 8129.00 & 8021.0 & 8786.00 & - \\
\hline MB12 & 125.00 & 125.00 & - & - & - & - \\
\hline Ba14 & 4665.93 & 4665.93 & 4780.91 & 4739.74 & 5004.55 & - \\
\hline Ma15a & 26800.63 & - & 27545.27 & - & 27545.30 & - \\
\hline Ma15s & 22871.97 & - & 23197.80 & - & 23197.80 & - \\
\hline AB20 & 5243.95 & 5256.10 & 5336.36 & 5297.6 & 5677.83 & - \\
\hline SC30 & 3519.44 & 3613.11 & 3443.34 & 3563.95 & & - \\
\hline SC35 & 4263.3 & 3885.29 & 3700.75 & - & - & - \\
\hline Du62 & 3713876.55 & - & 3641497.00 & - & - & - \\
\hline
\end{tabular}

Table 6

Summary of the results reached by the proposed CRO.

\begin{tabular}{lllll}
\hline Problem name & Best sol. & FBS Diff(\%) & STS Diff(\%) & Solution by CRO \\
\hline Slaughterhouse & $\mathbf{3 4 8 7 . 1 2}$ & $\mathbf{1 0 . 5 2}$ & $\mathbf{1 0 . 5 2}$ & $1|8-2| 4-5|12-7-6| 11-3-10-9$ \\
CartonPacks & $\mathbf{8 9 . 0 2}$ & $\mathbf{5 . 7 0}$ & $\mathbf{5 . 7 0}$ & $2-6-11|9-10-1-8| 5-4-7-3$ \\
ChoppedPlastic & $\mathbf{2 6 5 . 7 7}$ & $\mathbf{4 1 . 6 1}$ & $\mathbf{4 1 . 6 1}$ & $10-2-3-4-5-6-7 \mid 1-9-8$ \\
O7 & $\mathbf{1 3 4 . 1 6}$ & $\mathbf{0 . 0 2}$ & -1.93 & $3-5-7-8 \mid 1-4-6-2$ \\
O8 & $\mathbf{2 4 5 . 4 8}$ & $\mathbf{0 . 0 2}$ & -0.96 & $5-8-6-3 \mid 2-1-4-7$ \\
O9 & $\mathbf{2 3 9 . 4 4}$ & $\mathbf{0 . 6 9}$ & -1.37 & $5-9-6-2-3 \mid 8-1-4-7$ \\
Vc10Ra & $\mathbf{2 0 1 4 2 . 1 3}$ & $\mathbf{0 . 0 0}$ & -8.03 & $5-8-10-9-2-6-1 \mid-7-3$ \\
Vc10Rs & $\mathbf{2 2 8 7 1 . 9 7}$ & $\mathbf{1 . 4 3}$ & -12.86 & $7|5-10-9| 3|11| 12|8| 6|4-2| 1$ \\
Ba12 & $\mathbf{8 0 2 1 . 0}$ & $\mathbf{0 . 0 0}$ & $\mathbf{0 . 0 0}$ & $4-10|9-5-7| 3|2-12| 1 \mid 11-8-6$ \\
MB12 & $\mathbf{1 2 5 . 0 0}$ & $\mathbf{0 . 0 0}$ & $\mathbf{0 . 0 0}$ & $12|10-7-3-4-2-8-6-5-1-9| 11$ \\
Ba14 & $\mathbf{4 6 6 5 . 9 3}$ & $\mathbf{0 . 0 0}$ & -0.79 & $7-11-5|10| 1|3| 9|4-2| 13-1-4-12-8-6$ \\
Ma15a & $\mathbf{2 6 8 0 0 . 6 3}$ & $\mathbf{2 . 7 8}$ & $\mathbf{2 . 7 8}$ & $6-11|2-1-8-7-13| 4-15-3 \mid 5-14-12-10-9$ \\
Ma15s & $\mathbf{2 2 8 7 1 . 9 7}$ & $\mathbf{1 . 4 3}$ & $\mathbf{1 . 4 3}$ & $9-10-12-15-6-8-11-7|14-4-3-13| 5-2 \mid 1$ \\
AB20 & $\mathbf{5 2 4 3 . 9 5}$ & $\mathbf{0 . 2 3}$ & -11.20 & $1-16-11|17-13| 12-9-15|3-14| 19-10|6-4-2-7-20| 18-5$ \\
SC30 & 3519.44 & -2.16 & -4.73 & $19-34-30-10|2-6-22-26| 17-25-29-35-28-21 \mid 3-4-1-20$ \\
SC35 & 3885.29 & -4.74 & -14.63 & $19-34-30-10|2-6-22-26| 17-25-29-35-28-21 \mid 3-4-1-20$ \\
Du62 & 3713876.55 & -1.9 & -2.11 & $19-34-30-10|2-6-22-26| 17-25-29-35-28-21|3-4-1-20| 23-33-18-24-32 \mid$ \\
& & & & $13-15-7-11-8|12-34-9| 14-31-5-27-16$ \\
\hline
\end{tabular}

ison of our proposal against other works that use FBS in its approach. In particular, these FBS proposals are taken from PalomoRomero et al. (2017), Kulturel-Konak and Konak (2011), KulturelKonak (2012), Wong and Komarudin (2010) and Enea et al. (2005). Table 5 displays the results achieved by our proposal and the previous ones. For each UA-FLP, we have highlighted in bold the best solution. First, Table 5 shows that the proposed CRO algorithm is able to reach better results than the other compared FBS ap- proaches in most cases. As it was mentioned previously, the CRO 451 algorithm improves the results of 14 out of 17 tested problems. 452 Specifically, note that the suggested CRO approach obtains better 453 solutions than the approach by Enea et al. (2005) in all problems 454 compared: Slaughterhouse, Carton Packs and Chopped Plastic. The 455 CRO also obtained better results than the algorithm by Wong and 456 Komarudin (2010), in all cases of the seven problems in which we 457 compared with this approach. Also, compared with the algorithm 458 


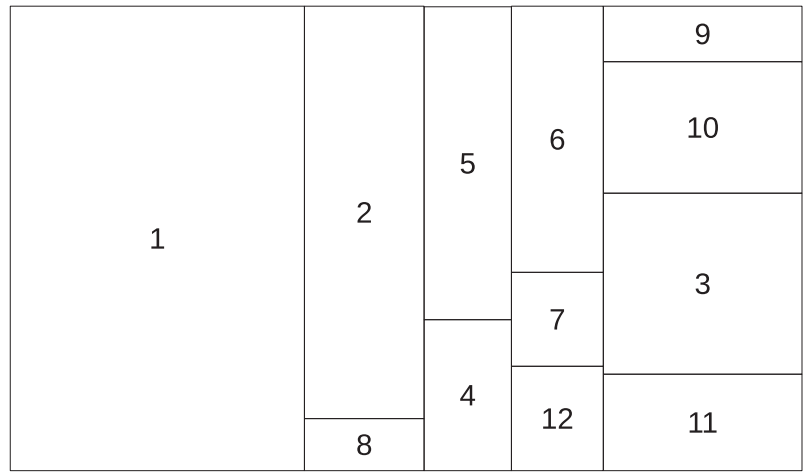

Fig. 13. Best design reached by the proposed CRO approach in the Slaughterhouse UA-FLP.

\begin{tabular}{|c|c|c|}
\hline 11 & & ? \\
\hline \multirow{2}{*}{6} & \multirow{3}{*}{1} & 7 \\
\hline & & \multirow{3}{*}{4} \\
\hline \multirow{3}{*}{2} & & \\
\hline & 10 & \\
\hline & 9 & 5 \\
\hline
\end{tabular}

Fig. 14. Best design reached by the proposed CRO approach in the CartonPacks UAFLP.

presented by Kulturel-Konak (2012), the CRO achieved better solutions in all of six problems in which we tested both algorithms. Additionally, our approach was able to obtain better or same solutions than the proposal by Kulturel-Konak and Konak (2011) in 7 out of 10 problems analyzed. Finally, our approach was capable to reach equal or better solutions than the proposal by PalomoRomero et al. (2017) in 10 out of 11 problems tested.

Considering FBS, the proposed CRO algorithm has been capable to equal or win previous algorithms results in most cases. The CRO has equalized the best result for three problems and has improved the best solution for other eleven UA-FLPs (considering a total of 17 test UA-FLPs). Note that we have demonstrated effectiveness of the suggested CRO algorithm when addressing small problems (it reaches better on all problems which have between 7 and 15 facil-

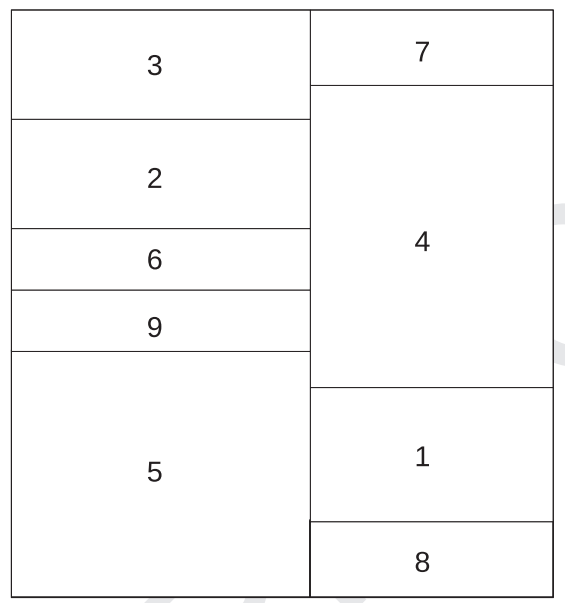

Fig. 16. Best design reached by the proposed CRO approach in the 09 UA-FLP.

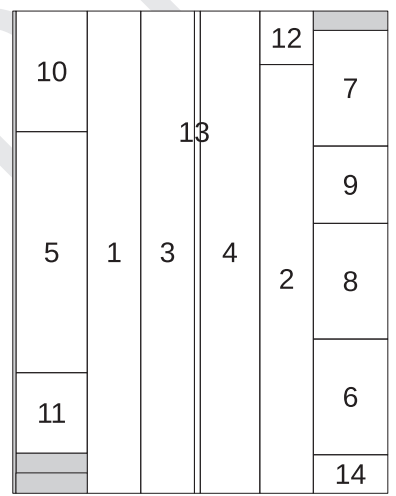

Fig. 17. Best design reached by the proposed CRO approach in the Ba14 UA-FLP.

ities, as Slaughterhouse, Carton Packs, Chopped Plastic, 07, 08, 09, 473 Vc10Ra, Vc10Rs, Ba12, MB12, Ba14, Ma15), solving medium prob- 474 lems (our CRO algorithm achieves better result on problem AB20 475 and very close result on SC30 which respectively have 20 and 30476 facilities), and also, addressing large problems (our CRO algorithm 477 is able to find solutions close to the best ones on problems SC35 478 and DU62 which respectively have 35 and 62 facilities). In contrast, 479 exclusively in the three problems (SC30, SC35 and DU62) where 480 our approach is not capable to achieve the best solution, the sug- 481 gested CRO algorithm is able to reach solutions very close to the 482 best known result taken from the references.

Moreover, Table 6 further compares the results reached by the CRO approach and the best known result obtained by other authors in related literature. This way, Table 6 shows the solution with best fitness produced by the suggested CRO approach, the difference (in percentage) between the solution with best fitness reached by the
473 4 775 6 77 878 79 80 82 483 484 485 486 487 488

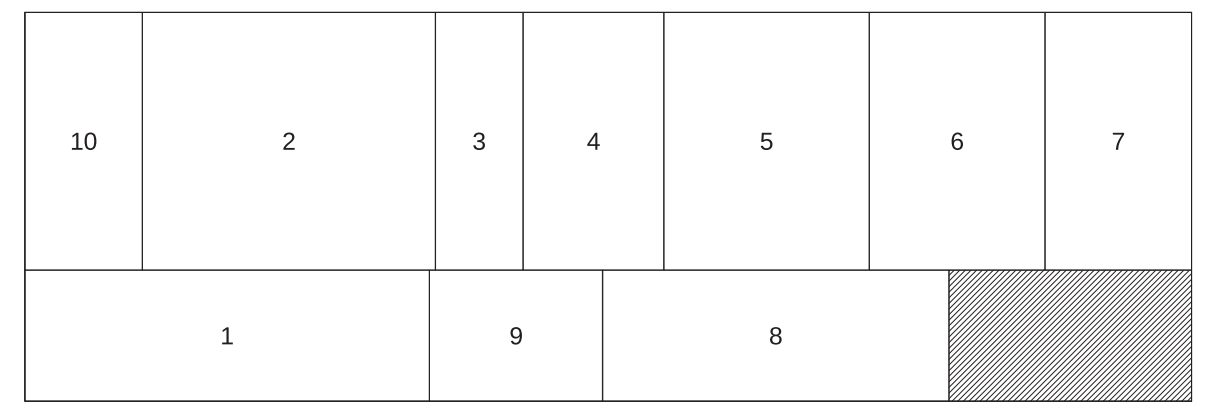

Fig. 15. Best design reached by the proposed CRO approach in the ChoppedPlastic UA-FLP. 


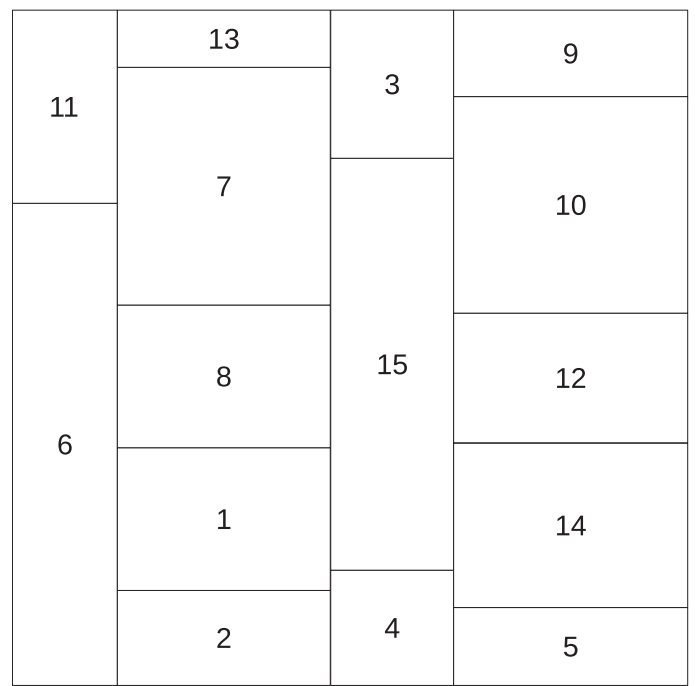

Fig. 18. The best design reach by the proposed CRO approach for ma15a UA-FLP.

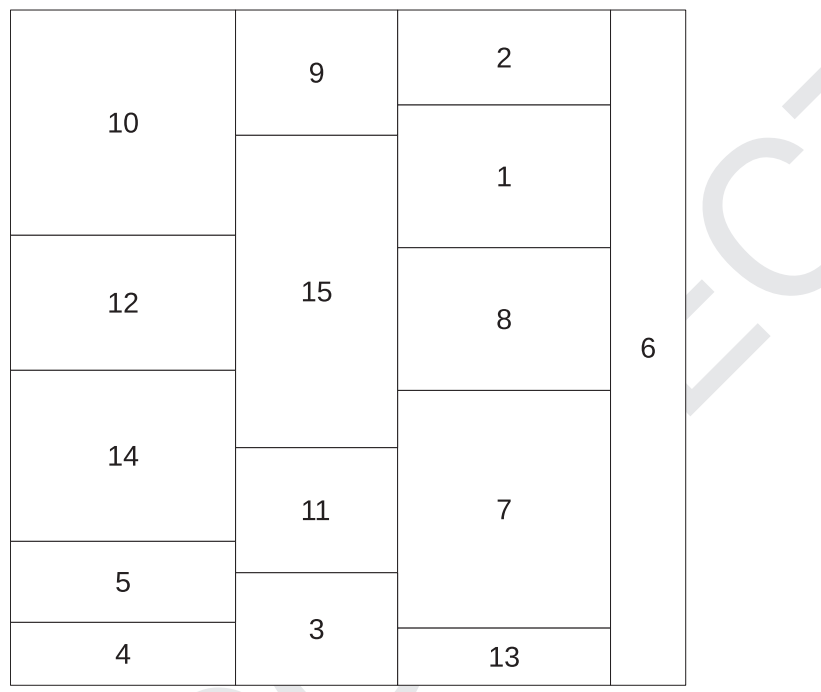

Fig. 19. The best design reach by the proposed CRO approach for ma15s UA-FLP.

CRO approach and the best known FBS result reached by previous works, and finally, this table presents the best facilities designs obtained by our CRO algorithm. In order to complete this table, examples of the facility layout solutions of the problems: Slaughterhouse, CartonPacks, ChoppedPlastic, 09, Ba14, ma15a and ma15s, that were generated by the proposed CRO algorithm and improved substantially the solutions than were reached by previous works, are respectively displayed in Figs. 13-19. These Figures offer the facility layout distribution of instances without empty space (as 09, ma15a and ma15s) and also, with empty space consideration (Ba14). As it was said previously, we have used the same definition of Ba14 that Komarudin and Wong (2010), in their work, it is specified that Ba14 is a problem with 14 facilities and 4 portions of remaining space which each one has an area equal to 0,5 .

It is well known that a correct plant layout design can increase efficiency and reduce industrial production costs in a very remarkable way. In this sense, the obtained results contribute to a significant improvement of industrial plants performance.

\section{Conclusions}

In this work, an evaluation of the performance of applying Coral Reefs Optimization to UA-FLPs considering FBS as representation structure, has been performed. From the best of our knowledge, is it the first time that CRO has been employed to solve UA-FLP. The proposed CRO approach has been applied to 17 UA-FLP instances taken from the related references, and its performance has been analyzed by comparison with different state-of-the-art approaches extracted from recent literature. From the empirical study carried out, we have found that the proposed CRO approach is able to reach or improve the best known results in 14 out of the 17 tested UA-FLPs when considering exclusively FBS representation. Moreover, our suggested proposal reaches or improves the best solution in 7 cases of the 17 tested problems when considering as layout representation both STS and FBS. In the remaining cases, our approach is able to reach solutions with results very close to the best known ones. This fact shows an excellent performance of the CRO algorithm when solving UA-FLPs.

A promising future line of work could be to add some qualitative preferences to the CRO algorithm. Furthermore, this research could be extended in order to take into account the possibility of adding additional considerations as, for example, the inclusion of aisles. Finally, another possible research direction could be to combine alternative methods of layout representation together with CRO for addressing UA-FLPs, and test advanced versions of the CRO approach (Salcedo-Sanz, 2017) in this problem.

\section{Conflict of interest}

The authors declare that there is no conflict of interests regarding the publication of this paper.

\section{Credit authorship contribution statement}

L. Garcia-Hernandez: Conceptualization, Data curation, Formal analysis, Funding acquisition, Investigation, Methodology, Project administration, Resources, Software, Supervision, Validation, Visualization, Writing - original draft, Writing - review \& editing. L. Salas-Morera: Conceptualization, Data curation, Formal analysis, Funding acquisition, Investigation, Methodology, Project administration, Resources, Software, Supervision, Validation, Visualization, Writing - original draft, Writing - review \& editing. J.A. Garcia-Hernandez: Conceptualization, Data curation, Formal analysis, Investigation, Methodology, Resources, Software, Visualization, Writing - review \& editing. S. Salcedo-Sanz: Conceptualization, Formal analysis, Funding acquisition, Investigation, Methodology, Project administration, Resources, Supervision, Validation, Visualization, Writing - original draft, Writing - review \& editing. J. Valente de Oliveira: Conceptualization, Formal analysis, Funding acquisition, Investigation, Methodology, Project administration, Resources, Supervision, Validation, Visualization, Writing - original draft, Writing - review \& editing.

\section{Acknowledgments}

This work has been partially supported by the project TIN201785887-C2-2-P of the Spanish Ministry of Economy, Industry and Competitiveness, Government of Spain. The authors acknowledge the funding by the program to promote research of the University of Córdoba (Spain), under the Research Project XXII PP. Mod. 4.1. The authors would like to thank the program to promote $\mathrm{PhD}$ mobility between international research institutions of the Spanish Education Ministry for funding part of this research under the program “José Castillejo2018”.
508 509 510 511 512 513 514 515 516 517 518 519 520 521 522 523 524 


\section{Appendix A. Data set for Slaughterhouse UA-FLP.}

This UA-FLP is a real case problem that was planned in the city of Córdoba (Spain). The facility plant dimensions are $30 \mathrm{~m} \times$ $51.14 \mathrm{~m}$. It was first described by Salas-Morera et al. (1996). Table 7 gives information about the department names, and also, their associated area and aspect ratio constraints. Fig. 20 details material handling flow between the facilities that made up the plant layout.

\section{Appendix B. Data set for CartonPacks UA-FLP.}

This UA-FLP is related to a carton recycling plant of $20 \mathrm{~m} \times$ $14.5 \mathrm{~m}$. It was described by García-Hernández et al. (2015). Briefly, Table 8 offers information about the department names, and also, their associated area and aspect ratio constraint. Fig. 21 details material handling flow between the facilities that made up the plant layout.

Table 7

Facility features for the Slaughterhouse problem.

\begin{tabular}{llll}
\hline Id & Facility & Area $\left(\mathrm{m}^{2}\right)$ & Aspect ratio \\
\hline A & Stables & 570 & 4 \\
B & Slaughter & 206 & 4 \\
C & Entrails & 150 & 4 \\
D & Leather \& skin & 55 & 4 \\
E & Aeration chamber & 114 & 4 \\
F & Refrigeration chamber & 102 & 4 \\
G & Entrails chamber & 36 & 4 \\
H & Boiler room & 26 & 4 \\
I & Compressor room & 46 & 4 \\
J & Shipping & 109 & 4 \\
K & Offices & 80 & 4 \\
L & Byproduct shipping & 40 & 4 \\
\hline
\end{tabular}

Table 8

\begin{tabular}{llll}
\hline Id & Facility & Area $\left(\mathrm{m}^{2}\right)$ & Aspect ratio \\
\hline A & Raw Material & 40 & 4 \\
B & Finished products & 40 & 4 \\
C & Mechanic & 20 & 4 \\
D & Offices & 50 & 4 \\
E & Staff WC & 20 & 4 \\
F & Expedition & 40 & 4 \\
G & Hydraulic 1 & 20 & 4 \\
H & Hydraulic 2 & 20 & 4 \\
I & Crushing & 20 & 4 \\
J & Circ. saw & 10 & 4 \\
K & Heat exchange & 10 & 4
\end{tabular}

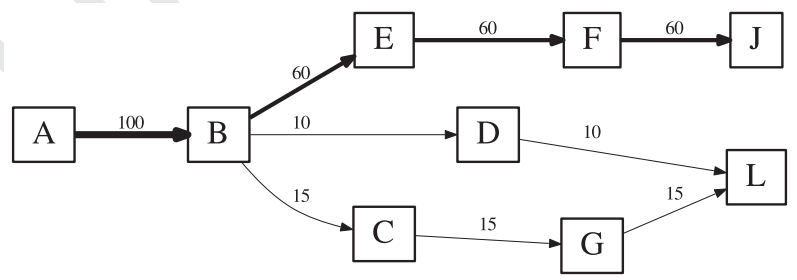

Fig. 20. Material flow requirements for the Slaughterhouse problem.

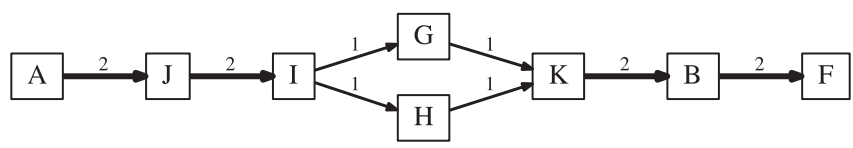

Fig. 21. Material flow requirements for the CartonPacks problem.
Table 9

Facility features for the ChoppedPlastic problem.

\begin{tabular}{llll}
\hline Id & Facility & Area $\left(\mathrm{m}^{2}\right)$ & Aspect ratio \\
\hline A & Reception & 35 & 4 \\
B & Raw material & 50 & 4 \\
C & Washing & 15 & 4 \\
D & Drying \& skin & 24 & 4 \\
E & Chopped & 35 & 4 \\
F & Finished product & 30 & 4 \\
G & Expedition & 25 & 4 \\
I & Office & 30 & 4 \\
J & Toilets & 15 & 4 \\
K & Repair shop & 20 & 4 \\
\hline
\end{tabular}

$\mathrm{A} \stackrel{10}{\longrightarrow} \mathrm{B} \stackrel{10}{\longrightarrow} \mathrm{C} \stackrel{10}{\longrightarrow} \mathrm{D} \stackrel{10}{\longrightarrow} \mathrm{E} \stackrel{10}{\longrightarrow} \mathrm{F} \stackrel{10}{\longrightarrow} \mathrm{G}$

Fig. 22. Material flow requirements for the ChoppedPlastic problem.

\section{Appendix C. Data set for ChoppedPlastic UA-FLP.}

This UA-FLP is related to a chopped plastic plant of $30 \mathrm{~m} \times$ $10 \mathrm{~m}$. It was described by García-Hernández et al. (2013a). Briefly, Table 9 offers information about the department names, and also, their associated area and aspect ratio constraint. Fig. 22 details material handling flow between the facilities that made up the plant layout.

\section{References}

Aiello, G., Enea, M., \& Galante, G. (2006). A multi-objective approach to facility layout problem by genetic search algorithm and electre method. Robotics and Computer-Integrated Manufacturing, 22, 447-455.

Aiello, G., Scalia, G. L., \& Enea, M. (2012). A multi objective genetic algorithm for the facility layout problem based upon slicing structure encoding. Expert Systems with Applications, (0).

Anjos, M. F., \& Vieira, M. V. (2017). Mathematical optimization approaches for facility layout problems: The state-of-the-art and future research directions. European Journal of Operational Research, 261(1), 1-16. doi:10.1016/j.ejor.2017.01.049.

Armour, G. C., \& Buffa, E. S. (1963). A heuristic algorithm and simulation approach to relative location of facilities. Management Science, 9, 294-309.

Azadivar, F., \& Wang, J. (2000). Facility layout optimization using simulation and genetic algorithms. International Journal of Production Research, 38(17), 4369-4383. doi:10.1080/00207540050205154.

Bazaraa, M. S. (1975). Computerized layout design: A branch and bound approach. A I I E Transactions, 7(4), 432-438.

Bermejo, E., Chica, M., Damas, S., Salcedo-Sanz, S., \& Cordón, O. (2018). Coral reef optimization with substrate layers for medical image registration. Swarm and Evolutionary Computation, 42, 138-159. doi:10.1016/j.swevo.2018.03.003.

Bozer, Y. A., \& Meller, R. D. (1997). A reexamination of the distancebased facility layout problem. IIE Transactions, 29(7), 549-560. doi:10.1080/ 07408179708966365.

Bozer, Y. A., Meller, R. D., \& Erlebacher, S. J. (1994). An improvement-type layout al932.

Camacho-Gómez, C., Wang, X., Pereira, E., Díaz, I., \& Salcedo-Sanz, S. (2018). Active vibration control design using the coral reefs optimization with substrate layer algorithm. Engineering Structures, 157, 14-26. doi:10.1016/j.engstruct.2017. 12.002 .

van Camp, D., Carter, M., \& Vannelli, A. (1992). A nonlinear optimization approach for solving facility layout problems. European Journal of Operational Research 57(2), 174-189.

Castillo, I., Westerlund, J., Emet, S., \& Westerlund, T. (2005). Optimization of block layout design problems with unequal areas: A comparison of MILP and MINLP optimization methods. Computers and Chemical Engineering, 30(1), 5469. doi:10.1016/j.compchemeng.2005.07.012.

Chae, J., \& Regan, A. C. (2016). Layout design problems with heterogeneous area constraints. Computers E' Industrial Engineering, 102, 198-207. doi:10.1016/j.cie. 2016.10.016.

Drira, A., Pierreval, H., \& Hajri-Gabouj, S. (2007). Facility layout problems: A survey Annual Reviews in Control, 31(2), 255-267. a facility layout problem. International Journal of Production Research, 41(15) 3479-3500. doi:10.1080/0020754031000118125.

Durán-Rosal, A. M., Gutiérrez, P. A., Salcedo-Sanz, S., \& Hervás-Martínez, C. (2018). A statistically-driven coral reef optimization algorithm for optimal size reduction of time series. Applied Soft Computing, 63, 139-153. doi:10.1016/j.asoc.2017.11. 037.
Facility features for the CartonPacks problem. gorithm for single and multiple-floor facilities. Management Science, 40(7), 918-

Dunker, T., Radons, G., \& Westkämper, E. (2003). A coevolutionary algorithm for 
Enea, M., Galante, G., \& Panascia, E. (2005). The facility layout problem approached using a fuzzy model and a genetic search. Journal of Intelligent Manufacturing, 16, 303-316. doi: 10.1007/s10845-005-7025-4.

Ficco, M., Esposito, C., Palmieri, F., \& Castiglione, A. (2018). A coral-reefs and game theory-based approach for optimizing elastic cloud resource allocation. Future Generation Computer Systems, 78, 343-352. doi:10.1016/j.future.2016.05.025.

García-Hernández, L., Arauzo-Azofra, A., Salas-Morera, L., Pierreval, H., \& Corchado, E. (2013a). Recycling plants layout design by means of an interactive genetic algorithm. Intelligent Automation E Soft Computing, 19(3), 457-468. doi:10.1080/10798587.2013.803679.

García-Hernández, L., Arauzo-Azofra, A., Salas-Morera, L., Pierreval, H., \& Corchado, E. (2015). Facility layout design using a multi-objective interactive genetic algorithm to support the DM. Expert Systems, 32(1), 94-107. doi:10.1111/ exsy.12064.

García-Hernández, L., Pierreval, H., Salas-Morera, L., \& Arauzo-Azofra, A. (2013b). Handling qualitative aspects in unequal area facility layout problem: An interactive genetic algorithm. Applied Soft Computing, 13(4), 1718-1727. doi:10.1016/j. asoc.2013.01.003.

García-Hernández, L., Palomo-Romero, J. M., Salas-Morera, L., Arauzo-Azofra, A., \& Pierreval, H. (2015). A novel hybrid evolutionary approach for capturing decision maker knowledge into the unequal area facility layout problem. Expert Systems with Applications, 42(10), 4697-4708. doi:10.1016/j.eswa.2015.01.037.

Goldberg, D. E., \& robert (1985). Alleles, loci, and the traveling salesman problem. In J. J. Grefenstette (Ed.), Proceedings of the first international conference on genetic algorithms and their applications. Lawrence Erlbaum Associates, Publishers. (pp. 154-159).

Gomez, A., Fernandez, Q. I., De la Fuente Garcia, D., \& Garcia, P. J. (2003). Using genetic algorithms to resolve layout problems in facilities where there are aisles. International Journal of Production Economics, 84(3), 271-282.

Gonçalves, J. F., \& Resende, M. G. (2015). A biased random-key genetic algorithm for the unequal area facility layout problem. European Journal of Operational Research, 246(1), 86-107. doi:10.1016/j.ejor.2015.04.029.

Holland, J. H. (1992). Adaptation in natural and artificial systems. Cambridge, MA, USA: MIT Press.

Hosseini-Nasab, H., Fereidouni, S., Fatemi Ghomi, S. M. T., \& Fakhrzad, M. B. (2018). Classification of facility layout problems: a review study. The International Journal of Advanced Manufacturing Technology, 94(1), 957-977. doi:10.1007/ s00170-017-0895-8.

Kang, S., \& Chae, J. (2017). Harmony search for the layout design of an unequal area facility. Expert Systems with Applications, 79, 269-281. doi:10.1016/j.eswa.2017. 02.047.

Komarudin, \& Wong, K. Y. (2010). Applying ant system for solving unequal area facility layout problems. European Journal of Operational Research, 202(3), 730-746. Konak, A., Kulturel-Konak, S., Norman, B., \& Smith, A. (2006). A new mixed integer formulation for optimal facility layout. Operation Research Letters, 34(6), 660672.

Kouvelis, P., Kurawarwala, A. A., \& Gutierrez, G. J. (1992). Algorithms for robust single and multiple period layout planning for manufacturing systems. European Journal of Operational Research, 63(2), 287-303.

Kulturel-Konak, S. (2012). A linear programming embedded probabilistic tabu search for the unequal-area facility layout problem with flexible bays. European Journal of Operational Research, 223(3), 614-625. doi:10.1016/j.ejor.2012.07.019.

Kulturel-Konak, S., \& Konak, A. (2011). A new relaxed flexible bay structure representation and particle swarm optimization for the unequal area facility layout problem. Engineering Optimization, 43(12), 1263-1287. doi:10.1080/0305215X. 2010.548864.

Liu, J., \& Liu, J. (2019). Applying multi-objective ant colony optimization algorithm for solving the unequal area facility layout problems. Applied Soft Computing, 74, 167-189. doi:10.1016/j.asoc.2018.10.012.

Liu, Q., \& Meller, R. D. (2007). A sequence-pair representation and mip-model-based heuristic for the facility layout problem with rectangular departments. IIE Transactions, 39(4), 377-394. doi:10.1080/07408170600844108.

Medeiros, I. G., Xavier, J. C., \& Canuto, A. M. P. (2015). Applying the coral reefs optimization algorithm to clustering problems. In 2015 international joint conference on neural networks (IJCNN) (pp. 1-8). doi:10.1109/IJCNN.2015.7280845.

Meller, R., Narayanan, V., \& Vance, P. (1998). Optimal facility layout design. Operations Research Letters, 23(3-5), 117-127.

Meller, R. D. (1997). The multi-bay manufacturing facility layout problem. International Journal of Production Research, 35(5), 1229-1237. doi:10.1080/ 002075497195290.

Meller, R. D., \& Gau, K.-Y. (1996). The facility layout problem: Recent and emerging trends and perspectives. Journal of Manufacturing Systems, 15(5), 351-366. doi:10.1016/0278-6125(96)84198-7.

Montreuil, B. (1991). A modelling framework for integrating layout design and flow network design. Material handling' 90. Berlin, Heidelberg: Springer Berlin Heidelberg. (pp. 95-115)

Paes, F. G., Pessoa, A. A., \& Vidal, T. (2017). A hybrid genetic algorithm with decomposition phases for the unequal area facility layout problem. European Journal of Operational Research, 256(3), 742-756. doi:10.1016/j.ejor.2016.07.022.

Palomo-Romero, J. M., Salas-Morera, L., \& García-a-Hernández, L. (2017). An island model genetic algorithm for unequal area facility layout problems. Expert Systems with Applications, 68, 151-162. doi:10.1016/j.eswa.2016.10.004.
Purnomo, M. R. A., \& Wiwoho, Y. S. (2016). Multi-objective mixed integer programming approach for facility layout design by considering closeness ratings, material handling, and re-layout cost. IOP Conference Series: Materials Science and Engineering, 105, 012045. doi:10.1088/1757-899x/105/1/012045.

Salas-Morera, L., Cubero-Atienza, A., \& Ayuso-Munoz, R. (1996). Computer-aided plant layout | Distribucion en planta asistida por ordenador. Informacion Tecnologica, 7(4), 39-46.

Salcedo-Sanz, S. (2017). A review on the coral reefs optimization algorithm: new development lines and current applications. Progress in Artificial Intelligence, 6(1), 1-15. doi:10.1007/s13748-016-0104-2.

Salcedo-Sanz, S., Camacho-Gómez, C., Mallol-Poyato, R., Jiménez-Fernández, S., \& DelSer, J. (2016). A novel coral reefs optimization algorithm with substrate layers for optimal battery scheduling optimization in micro-grids. Soft Computing, 20(11), 4287-4300.

Salcedo-Sanz, S., Camacho-Gómez, C., Magdaleno, A., Pereira, E., \& Lorenzana, A. (2017). Structures vibration control via tuned mass dampers using a co-evolution coral reefs optimization algorithm. Journal of Sound and Vibration, 393, 62-75. doi:10.1016/j.jsv.2017.01.019.

Salcedo-Sanz, S., Del Ser, J., Landa-Torres, I., Gil-López, S., \& PortillaFigueras, A. (2013). The coral reefs optimization algorithm: an efficient meta-heuristic for solving hard optimization problems. In Proceedings of the 15th international conference on applied stochastic models and data analysis (ASMDA2013), Mataró (pp. 751-758).

Salcedo-Sanz, S., Del Ser, J., Landa-Torres, I., Gil-López, S., \& PortillaFigueras, J. A. (2014a). The coral reefs optimization algorithm: A Novel metaheuristic for efficiently solving optimization problems. Scientific World Journal, 2014. doi:10.1155/2014/739768.

Salcedo-Sanz, S., García-Díaz, P., Portilla-Figueras, J., Ser, J. D., \& GilLópez, S. (2014b). A coral reefs optimization algorithm for optimal mobile network deployment with electromagnetic pollution control criterion. Applied Soft Computing, 24, 239-248. doi:10.1016/j.asoc.2014.07.007.

Salcedo-Sanz, S., Pastor-Sánchez, A., Prieto, L., Blanco-Aguilera, A., \& GarcíaHerrera, R. (2014c). Feature selection in wind speed prediction systems based on a hybrid coral reefs optimization - extreme learning machine approach. Energy Conversion and Management, 87, 10-18. doi:10.1016/j.enconman.2014.06. 041.

Salcedo-Sanz, S., Sanchez-Garcia, J., J. A. , P.-F., Jimenez-Fernandez, S., \& Ahmadzadeh, A. (2014d). A coral-reef optimization algorithm for the optimal service distribution problem in mobile radio access networks. Transactions on Emerging Telecommunications Technologies, 25(11), 1057-1069. doi:10.1002/ett. 2759.

Saraswat, A., Venkatadri, U., \& Castillo, I. (2015). A framework for multi-objective facility layout design. Computers $\mathcal{E}$ Industrial Engineering, 90, 167-176. doi:10. 1016/j.cie.2015.09.006.

Scholz, D., Petrick, A., \& Domschke, W. (2009). Stats: A slicing tree and tabu search based heuristic for the unequal area facility layout problem. European Journal of Operational Research, 197(1), 166-178.

See, P. C., \& Wong, K. Y. (2008). Application of ant colony optimisation algorithms in solving facility layout problems formulated as quadratic assignment problems: a review. International Journal of Industrial and Systems Engineering, 3(6), 644-672.

Shayan, E., \& Chittilappilly, A. (2004). Genetic algorithm for facilities layout problems based on slicing tree structure. International Journal of Production Research, 42(19), 4055-4067, doi:10.1080/00207540410001716471.

Sherali, H., Fraticelli, B., \& Meller, R. (2003). Enhanced model formulations for optimal facility layout. Operations Research, 51, 629-644.

Sikaroudi, A. M. E., \& Shahanaghi, K. (2016). Facility layout by collision detection and force exertion heuristics. Journal of Manufacturing Systems, 41, 21-30. doi:10.1016/j.jmsy.2016.07.001.

Tam, K. Y. (1992). A simulated annealing algorithm for allocating space to manufacturing cells. International Journal of Production Research, 30(1), 63-87. doi:10. 1080/00207549208942878.

Tate, D. M., \& Smith, A. E. (1995). Unequal area facility layout using genetic search. IIE Transactions, 27, 465-472.

Tompkins, J., White, J., Bozer, Y., \& Tanchoco, J. (2010). Facilities Planning (4th). New York: Wiley.

Tong, X. (1991). SECOT: A sequential construction technique for facility design. University of Pittsburg: Doctoral Dissertation.

Ulutas, B. H., \& Kulturel-Konak, S. (2012). An artificial immune system based algorithm to solve unequal area facility layout problem. Expert Systems with Applications, 39(5), 5384-5395.

Wong, K. Y., \& Komarudin (2010). Solving facility layout problems using flexible bay structure representation and ant system algorithm. Expert Systems with Applications, 37(7), 5523-5527. doi:10.1016/j.eswa.2009.12.080.

Wu, Y., \& Appleton, E. (2002). The optimisation of block layout and aisle structure by a genetic algorithm. Computer Industrial Engineering, 41(4), 371-387.

Yan, C., Ma, J., Luo, H., \& Patel, A. (2019). Hybrid binary coral reefs optimization algorithm with simulated annealing for feature selection in high-dimensional biomedical datasets. Chemometrics and Intelligent Laboratory Systems, 184, 102111. doi:10.1016/j.chemolab.2018.11.010

Yang, Z., Zhang, T., \& Zhang, D. (2016). A novel algorithm with differential evolution and coral reef optimization for extreme learning machine training. Cognitive Neurodynamics, 10(1), 73-83. doi:10.1007/s11571-015-9358-9. 